\title{
Impact of HIV on VA Dental Services: Report of a Survey
}

Michael C. Manz, DDS, MPH

Program in Dental Public Health

University of Michigan School of Public Health

109 Observatory

Ann Arbor, MI 48109

Robert J. Weyant, DMD, DrPH

Department of Public Health and Community Dentistry

School of Dental Medicine, University of Pittsburgh, and

VA Medical Center

Pittsburgh, PA

Richard Adelson, DDS

Director

Department of Veterans Affairs Regional Medical Educational Center

Minneapolis, MN

Susan K. Sverha, RN, MSN

National Coordinator HIV/AIDS Education

Office of Academic Affairs

Department of Veterans Affairs Central Office

J. Richard Durnan, DDS

Chair

OAA HIVIAIDS Education Working Group

Department of Veterans Affairs Regional Medical Education Center

Northport, NY

Michael J. Geboy, PhD

Assistant Director for Education

Department of Veterans Affairs Eastern Dental Education Center

Washington, DC

Abstract

Objectives: This study assessed knowledge, attitudes, and behaviors related to the treatment of HIV-infected patients by Department of Veterans Affairs (VA) dental personnel. Methods: A questionnaire was mailed to all VA dentists, hygienists, and EFDA assistants and completed anonymously in May 1991. Descriptive results are reported along with comparisons between the findings from this study and a similar VA survey conducted in 1988, as well as several national surveys of non-VA dentists. Results: Nearly all VA respondents reported participation in some type of continuing education on HIV and infection control. They also reported high compliance

Send correspondence and reprint requests to Dr. Manz. Manuscript received: $7 / 26 / 93$; returned to authors for revision: 10/7/93; accepted for publication: $4 / 6 / 94$. with recommended infection control procedures. Furthermore, the findings suggest that VA dentists and hygienists have a high willingness to treat HIV-infected patients, far exceeding that expressed by non-VA dentists. However, a high level of anxiety related to occupational exposure to HIV seems to exist. Most respondents perceived a higher risk of HIV infection from commonly encountered occurrences in the workplace than actually exists based on current knowledge. Conclusions: While efforts to further reduce the risk of infection and improve care should continue, future efforts also should be directed toward reducing the anxiety of VA dental personnel in the treatment of infectious patients.

Key Words: suney, dental, attitudes, behaviors, HIV, infectious patients. 
In 1991, the Department of Veterans Affairs' Office of Academic Affairs and Eastern Dental Education Center completed a survey of VA dental personnel to describe attitudes and behaviors regarding HIV and to assess the effect of HIV on dental practice within the VA. This initiative followed a 1988 study conducted in part to evaluate the effects of VA continuing education (CE) programs on positive outcomes related to the treatment of infectious patients. Ultimately, the results of the 1991 study would be used to guide policy development and educational initiatives directed at improving patient care. This paper focuses on the 1991 survey results and, where possible, compares 1991 results with the results from the 1988 VA survey as well as similar non-VA surveys such as the 1988 American Dental Association (ADA) national survey of private practitioners (1).

\section{Methods}

Two versions of an anonymous, self-administered questionnaire were developed for distribution, one going to VA dentists, and the other to VA dental hygienists and expanded function dental auxiliaries (EFDAs), hereafter referred to as hygienist/EFDAs. Certified dental assistants and registered dental hygienists are trained by the VA to work as EFDAs within the VA system.

Both versions of the 1991 questionnaire essentially were identical across the majority of items, although the phrasing of several items was altered slightly in the hygienist/EFDAs' questionnaire to better reflect their relationships to dentists and patients. Useful items from the 1988 VA survey instrument were included so that change occurring between the surveys could be assessed. New items were included to gain other information of interest. The questionnaire was pretested with feedback from several dentists to ensure that only items of sufficient clarity and informative value were included in the final questionnaire.

The questionnaires contained over 150 items designed to measure various aspects of the respondent's behaviors, knowledge, and attitudes regarding HIV-related issues. The principal areas addressed in the survey were: infection control, clinical practice behaviors, HIV continuing education, attitudes and beliefs related to the care of HIV-infected patients, occupational exposure to infectious agents, and knowledge of HIV and its oral manifestations. Responses to attitudinal questions were collected using six-point Likert scales anchored at "strongly agree" and "strongly disagree."

Questionnaires were mailed to all VA dentists $(N=885)$ and VA hygienist/EFDAs $(N=156)$ with return envelopes and instructions on survey completion. The survey was conducted so as to ensure total anonymity of respondents due to the sensitive nature of questionnaire items. Therefore, individual follow-up on nonrespondents was not possible. However, several reminders to complete and return the questionnaires were issued through the dental clinic chiefs.

Responses were entered into a database program, checked for entry errors, and transferred to a statistical analysis package (SAS). Analysis for this paper included simple descriptive statistics in the form of frequency distributions and means. This analysis was conducted to describe the survey population and compare the results with the 1988 VA survey population and with other non-VA dental personnel survey populations.

Both this survey and the 1988 survey were complete target population enumerations of all VA dentists, hygienists, and EFDA assistants. Therefore, sampling error is not present and statistical inference from a sample to a population is not necessary. The survey means and proportions are the true means and proportions for the population, except for possible error due to measurement and nonresponse.

\section{Results}

Completed questionnaires were returned by 553 (62.5\%) of the 885 dentists and $132(84.6 \%)$ of the 156 hygienist/EFDAs. In 1991 dentists reported a mean age of 45.6 years and a mean number of years in practice of 19.5 years, similar to the mean age of 45.8 and mean number of years in practice of 19.0 in 1988. Responding hygienists/EFDAs averaged 41.0 years of age in 1991, almost identical to the mean age of 41.1 in 1988. Mean number of years in practice was greater for hygienists/EFDAs in 1991 (18.4 years) than in 1988 (16.2 years). Other characteristics of responding dentists and hygienist/EFDAs are displayed in Table 1 for both surveys. Though nonresponse bias could not be evaluated directly because of the anonymous nature of the survey, respondents were very similar to the overall VA dental population when compared on basic characteristics such as age, sex, and years of service using available information.

$C E$ experience and major sources of information of respondents on HIV and infection control are shown in Tables 2 and 3 . The vast majority of respondents have participated in CE courses on AIDS and HIV, with an increase between 1988 and 1991. CE courses were the main source of information on AIDS and HIV, while VA publications, guidelines, and seminars have more importance in providing information on infection control to dentists.

Nearly all VA dental personnel had some experience in the treatment of HIV-infected patients. About 96 percent of dentists and 90 percent of hygienist/EFDAs reported treating patients who they knew to be HIV positive, with 23 percent of dentists and 19 percent of hygienist /EFDAs reporting having treated more than 10 known HIV-infected patients in the past year.

Potential exposure to bloodborne pathogens was common and is summarized in Table 4. Between 1988 and 1991, proportions reporting dental instrument injuries increased for both dentists and hygienist/EFDAs, as did 
TABLE 1

Number and Percent Distribution of Respondents by Sex, Type of Practice, Type Personnel, and Survey Year

\begin{tabular}{|c|c|c|c|c|}
\hline & \multicolumn{2}{|c|}{1988} & \multicolumn{2}{|c|}{1991} \\
\hline & $n$ & $\%$ & $n$ & $\%$ \\
\hline \multicolumn{5}{|l|}{ Dentists } \\
\hline \multicolumn{5}{|l|}{ Sex } \\
\hline Male & 564 & 94.9 & 510 & 92.2 \\
\hline Female & 30 & 5.1 & 41 & 7.4 \\
\hline \multicolumn{5}{|l|}{ Type of practice } \\
\hline General dentistry & 446 & 75.2 & 383 & 69.6 \\
\hline Endodontics & 5 & 0.8 & 8 & 1.5 \\
\hline Prosthodontics & 65 & 11.0 & 62 & 11.3 \\
\hline Periodontics & 27 & 4.6 & 34 & 6.2 \\
\hline Oral/maxillofacial surgery & 43 & 7.3 & 37 & 6.7 \\
\hline Oral pathology & 2 & 0.3 & 3 & 0.5 \\
\hline Public health & 2 & 0.3 & 1 & 0.2 \\
\hline Geriatrics & * & $*$ & 16 & 2.9 \\
\hline Other & 3 & 0.5 & 6 & 1.1 \\
\hline \multicolumn{5}{|l|}{ Hygienists/EFDAs } \\
\hline \multicolumn{5}{|l|}{ Sex } \\
\hline Male & 6 & 5.0 & 9 & 6.8 \\
\hline Female & 115 & 95.0 & 123 & 93.2 \\
\hline \multicolumn{5}{|l|}{ Type of practice } \\
\hline EFDA assistant & 21 & 18.6 & 6 & 4.6 \\
\hline EFDA hygienist & 29 & 25.7 & 15 & 11.5 \\
\hline Dental hygienist & 63 & 55.8 & 109 & 82.6 \\
\hline
\end{tabular}

*Category not included in survey.

TABLE 2

Percent of Respondents Reporting Attendance at CE Courses, by Personnel Type and Survey Year

\begin{tabular}{|c|c|c|}
\hline & $1988(\%)$ & $1991(\%)$ \\
\hline \multicolumn{3}{|c|}{ Attended one or more courses on AIDS/HIV } \\
\hline Dentists & 83.5 & 96.9 \\
\hline Hygienist/EDFAs & 88.2 & 97.7 \\
\hline \multicolumn{3}{|c|}{ Attended three or more courses on AIDS/HIV } \\
\hline Dentists & 36.4 & 78.5 \\
\hline Hygienist/EDFAs & 51.3 & 81.1 \\
\hline
\end{tabular}

TABLE 3

Percent of Respondents Reporting Information Sources about AIDS or HIV and Infection Control, by Personnel Type, 1991

\begin{tabular}{|c|c|c|}
\hline & Dentists (\%) & $\begin{array}{l}\text { Hygienist/ } \\
\text { EFDAs (\%) }\end{array}$ \\
\hline \multicolumn{3}{|c|}{ Main source of information about AIDS/HIV } \\
\hline Continuing education courses & 31.3 & 34.1 \\
\hline $\begin{array}{l}\text { Articles in professional } \\
\text { journals }\end{array}$ & 30.4 & 19.2 \\
\hline Inservice VA seminars & 11.9 & 25.8 \\
\hline $\begin{array}{l}\text { VA publications and policy } \\
\text { guidelines }\end{array}$ & 11.6 & 9.1 \\
\hline Articles in public media & 3.4 & 4.5 \\
\hline $\begin{array}{l}\text { Public health officials/ } \\
\text { publications }\end{array}$ & 2.5 & 0.8 \\
\hline $\begin{array}{l}\text { Informal consultation with } \\
\text { other professionals }\end{array}$ & 2.0 & 3.0 \\
\hline \multicolumn{3}{|c|}{ Main source of information about infection control } \\
\hline $\begin{array}{l}\text { VA publications and policy } \\
\text { guidelines }\end{array}$ & 27.3 & 20.5 \\
\hline Continuing education courses & 20.3 & 28.8 \\
\hline Inservice VA seminars & 20.1 & 27.3 \\
\hline $\begin{array}{l}\text { Articles in professional } \\
\text { journals }\end{array}$ & 19.2 & 9.1 \\
\hline $\begin{array}{l}\text { Public health officials/ } \\
\text { publications }\end{array}$ & 2.7 & 1.5 \\
\hline $\begin{array}{l}\text { Informal consultation with } \\
\text { other professionals }\end{array}$ & 2.0 & 2.3 \\
\hline Articles in public media & 0.7 & 1.5 \\
\hline
\end{tabular}

the proportion of dentists experiencing needlesticks. About one in four respondents have sought medical evaluation or care because of these exposures, with 47 percent of the dentists and 35 percent of the hygienist/EFDAs believing they had experienced exposures that could have resulted in HIV infection. Also, 46 percent of dentists and 33 percent of hygienist/EFDAs have been tested for HIV, with 19 percent of the dentists and 17 percent of the hygienist/EFDAs indicating that HIV testing was sought as a direct result of concern over

TABLE 4

Number and Percent of Respondents Reporting One or More Exposures during Previous Year

\begin{tabular}{|c|c|c|c|c|c|c|c|c|}
\hline \multirow[b]{3}{*}{ Type of Exposure } & \multicolumn{4}{|c|}{ Dentists } & \multicolumn{4}{|c|}{ Hygienist/EFDAs } \\
\hline & \multicolumn{2}{|c|}{1988} & \multicolumn{2}{|c|}{1991} & \multicolumn{2}{|c|}{1988} & \multicolumn{2}{|c|}{1991} \\
\hline & $n$ & $\%$ & $n$ & $\%$ & $n$ & $\%$ & $n$ & $\%$ \\
\hline Needlesticks & 139 & 23.9 & 162 & 29.6 & 24 & 20.3 & 19 & 14.4 \\
\hline Splashes & 339 & 67.3 & 287 & 52.5 & 67 & 61.5 & 60 & 45.8 \\
\hline Dental instrument injuries & 206 & 35.8 & 337 & 61.3 & 61 & 51.3 & 91 & 68.9 \\
\hline
\end{tabular}


FIGURE 1

Dentists' Perceived Risk of Infection from Needlestick While Treating Infected Patient

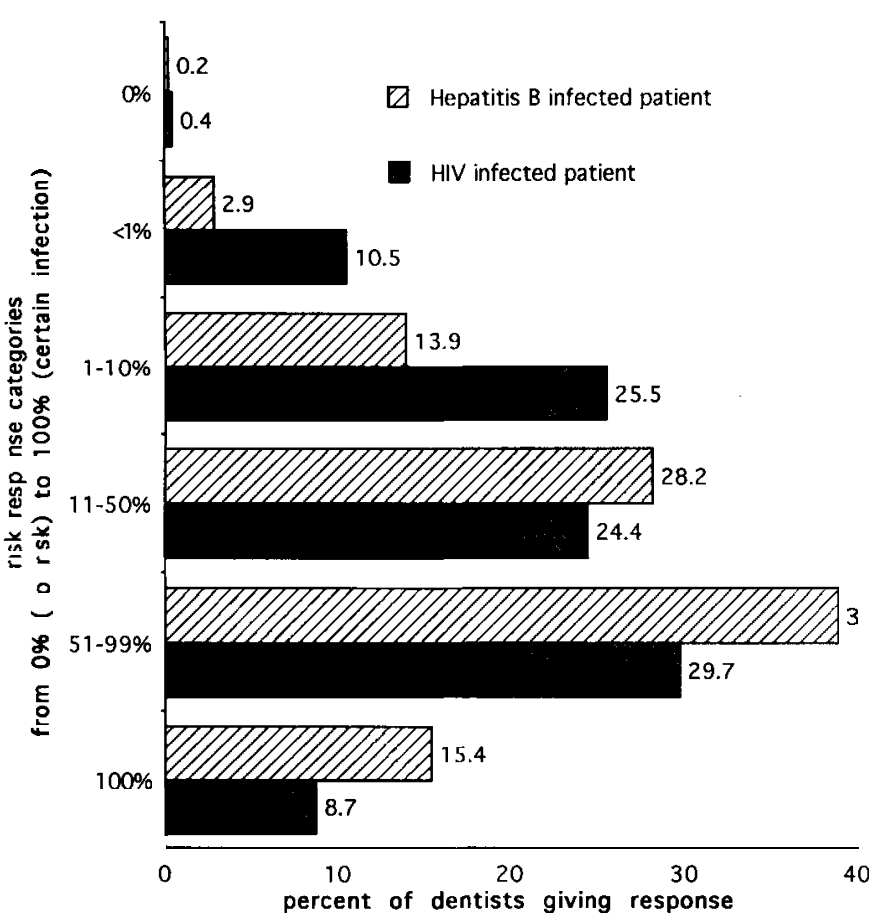

FIGURE 2

Hygienist/EFDAs' Perceived Risk of Infection from Needlestick While Treating Infected Patient

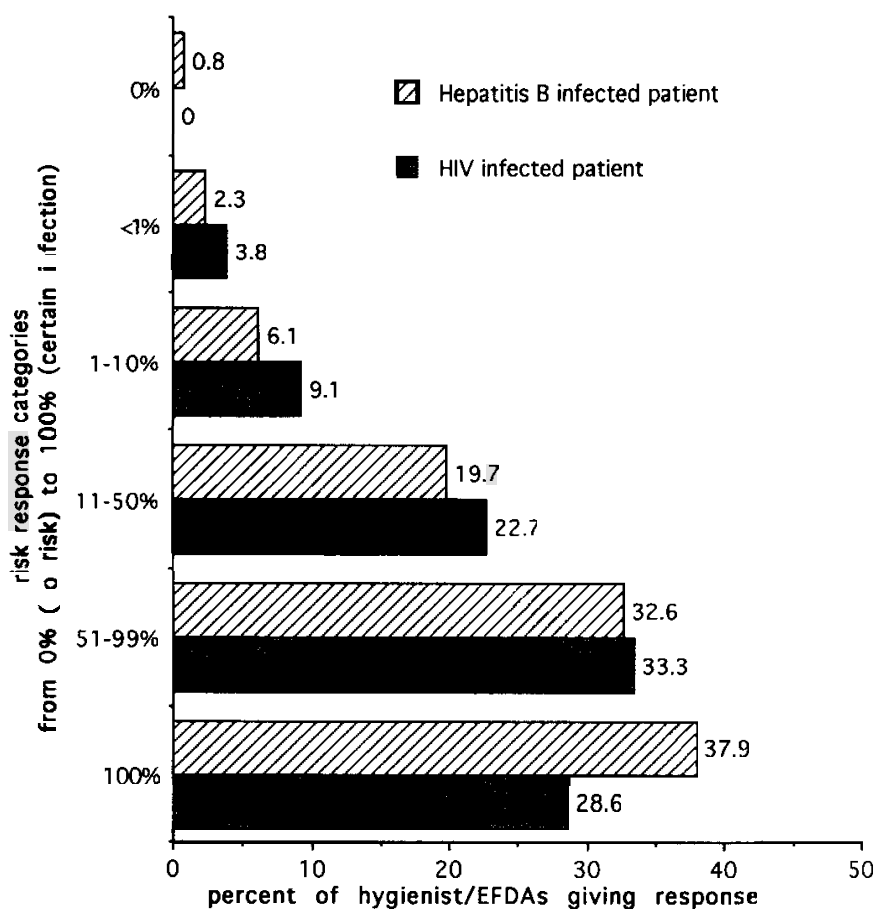

TABLE 5

Percent Distribution of Dentists' Responses on Frequency of Various Clinical Infection Control Activities during Patient Treatment

\begin{tabular}{|c|c|c|c|c|}
\hline Clinical Infection Control Activities & Always & $\begin{array}{l}\text { Almost } \\
\text { Always }\end{array}$ & Sometimes & Never \\
\hline Wear protective gloves & 94.2 & 4.3 & 0.5 & 0 \\
\hline Wash hands before gloving and after removing gloves & 64.0 & 27.8 & 6.9 & 0.5 \\
\hline Change to a new pair of gloves between each patient & 98.2 & 0.7 & 0.2 & 0 \\
\hline $\begin{array}{l}\text { Wear a surgical mask or other facial barrier when the splattering } \\
\text { of body fluids is likely }\end{array}$ & 89.9 & 6.3 & 2.9 & 0 \\
\hline Wear eye protection when the splattering of body fluids is likely & 92.4 & 4.9 & 1.8 & 0.2 \\
\hline Wear surgical gown & 19.3 & 15.0 & 51.2 & 13.6 \\
\hline $\begin{array}{l}\text { Sterilize (as opposed to disinfect) hand pieces before use on each } \\
\text { patient (you or another staff person) }\end{array}$ & 67.3 & 12.3 & 14.8 & 4.7 \\
\hline $\begin{array}{l}\text { Wipe down operatory equipment and countertops with } \\
\text { recommended (e.g., ADA, CDC) surface disinfectants for each } \\
\text { patient (you or another staff person) }\end{array}$ & 66.7 & 23.9 & 8.1 & 0.5 \\
\hline
\end{tabular}

occupational exposure.

Results indicated a high perceived risk of infection from percutaneous injuries (sticks) from needles used on infected patients, with over 38 percent of dentists believing the risk of HIV infection to be over 50 percent, and over 54 percent believing the risk of hepatitis $B$ infection to be over 50 percent (Figure 1). Even higher perceived risk from needlesticks is seen in hygienist/EFDAs (Figure 2). Furthermore, 9 percent of dentists and 29 percent of hygienist/EFDAs believed that sustaining such an injury during treatment of an HIV-infected patient would result in certain infection.

The perceived risk for working as a VA operative dentist for one year was low, with the majority of respondents putting the risk at less than 1 percent, although almost 16 percent of the respondents did estimate the risk to be greater than 1 percent. Similar results were seen for perceived risk associated with working in their present positions for one year. Results indicated that hygienist/EFDAs perceived a higher personal risk of HIV infec- 
TABLE 6

Percent Distribution of Hygienist/EFDAs' Responses on Frequency of Various Clinical Infection Control Activities during Patient Treatment

\begin{tabular}{|c|c|c|c|c|}
\hline Clinical Infection Control Activities & Always & $\begin{array}{l}\text { Almost } \\
\text { Always }\end{array}$ & Sometimes & Never \\
\hline Wear protective gloves & 97.0 & 1.5 & 0 & 0 \\
\hline Wash hands before gloving and after removing gloves & 75.8 & 20.5 & 2.3 & 0 \\
\hline Change to a new pair of gloves between each patient & 97.7 & 0 & 0.8 & 0 \\
\hline $\begin{array}{l}\text { Wear a surgical mask or other facial barrier when the splattering } \\
\text { of body fluids is likely }\end{array}$ & 94.7 & 2.3 & 1.5 & 0 \\
\hline Wear eye protection when the splattering of body fluids is likely & 90.9 & 4.5 & 3.0 & 0 \\
\hline Wear surgical gown & 33.3 & 8.3 & 38.6 & 16.7 \\
\hline $\begin{array}{l}\text { Sterilize (as opposed to disinfect) handpieces before use on each } \\
\text { patient (you or another staff person) }\end{array}$ & 63.6 & 15.2 & 17.4 & 1.5 \\
\hline $\begin{array}{l}\text { Wipe down operatory equipment and countertops with } \\
\text { recommended (e.g., ADA, CDC) surface disinfectants for each } \\
\text { patient (you or another staff person) }\end{array}$ & 84.1 & 9.8 & 3.0 & 0.8 \\
\hline
\end{tabular}

tion than dentists.

There was a surprisingly high perceived risk of HIV infection from being sneezed on by an HIV-infected person, with 16 percent of dentists and 20 percent of hygienist/EFDAs putting the risk at over 10 percent. Administering CPR to, being bitten by, or being splashed with blood from an HIV-infected individual were rated as high-risk occurrences. Low risk was felt for shaking hands and day-to-day work interactions with HIV-infected individuals. A greater perceived risk of hepatitis B infection than HIV infection generally was found.

A general sense of the anxiety caused by HIV appears in responses to an item that asked about the career choice of respondents. About 34 percent of the dentists and almost 40 percent of the hygienist/EFDAs agreed that they would not go into a profession involving exposure to HIV-infected persons if they had it to do over again. Over half of the respondents indicated they enjoyed their jobs less now because of fear of HIV exposure.

Tables 5 and 6 indicate that compliance with recommended infection control practices for both VA dentists and hygienist/EFDAs was high. Most VA dental personnel (90\% for dentists and $94 \%$ for hygienist / EFDAs) also have been vaccinated for hepatitis $B$. Most responding dentists reported being familiar and comfortable with guidelines provided by the ADA, CDC, OSHA, and VA. About 5 percent of dentists and 11 percent of hygienist/EFDAs indicated they were not familiar with CDC's "Recommended Infection Control Practices for Dentistry" (2-4).

A question to determine the perceived effectiveness of infection control activities showed that most dentists believed recommended practices were adequate to protect themselves and other patients from infection. Almost one-third of dentists, however, agreed to some extent that these recommended practices were inadequate. Simi-
FIGURE 3

Percent Distribution of Responses to Statement that Respondents Would Treat HIV-infected Persons Even If Option for Legitimate Referral Existed

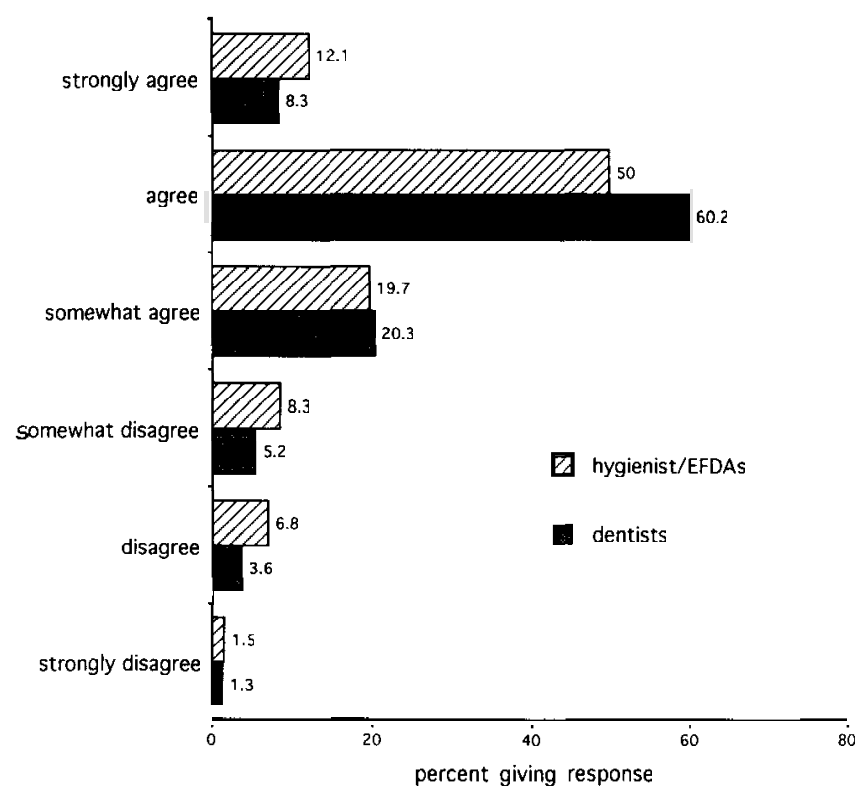

larly, about 22 percent of the dentists and 18 percent of hygienist/EFDAs did not agree that the chances of becoming HIV-infected were "negligible" even when recommended infection control practices were followed. There also was the belief that infection control practices were more adequate in protecting other patients from cross infection than in protecting treating dentists.

Many items in the questionnaire were designed to provide information aboutgeneral attitudes of VA dental personnel regarding HIV-infected patients and dental treatment of these patients. About 95 percent of respon- 
dents agreed that HIV patients deserve our compassion. A slightly lower percent of dentists (83\%) and hygienist/EFDAs (89\%) agreed that these patients deserve the same access to care as others. About two of three respondents agreed with the ADA policy that it is unethical to deny treatment based solely on HIV infection status. However, over half of dentists and hygienist/EFDAs agreed with a statement that they should have the right to decide whether to accept an HIV-infected person as a patient.

In items addressing the obligation to treat patients, the highest percentage of dentists agreed that a "professional" obligation exists ( $86 \%$ ), with declining agreement on the existence of a "moral" (80\%) or "legal" $(67 \%)$ obligation to treat. Over half of the dentists disagreed with the statement that they "should have a legal obligation" to treat.

The effects of HIV on clinical behavior were explored in several questionnaire items. Over half the respondents reported that their confidence in treating patients was adversely affected by not having full access to information on the HIV status of their patients, and that their care or treatment planning for HIV-infected persons has been influenced by the risk of HIV infection. Dentists $(80 \%)$ also indicated that their treatment planning for HIV-infected individuals has been influenced by the poor medical prognosis of these patients.

Over half of the respondents indicated they felt uncomfortable asking patients about risk factors for HIV infection. The majority of respondents also thought, however, that they would become more comfortable in treating HIV-infected patients as time goes on. The level of agreement of respondents on feeling uncomfortable treating various types of patients listed in the questionnaire from highest to lowest was: HIV-infected persons, illicit drug users, homosexuals, terminally ill patients, new patients, and elderly patients. Similar results were found for hygienist/EFDAs. In an item specifically addressing attitudes toward treatment of homosexual patients, 22 percent of dentists and 16 percent of hygienist/EFDAs agreed that they felt less comfortable treating homosexuals with AIDS than other AIDS patients.

Several items were included in the questionnaire to evaluate willingness of VA dental personnel to treat HIVinfected patients. The simple question "Will you treat an HIV-infected patient?" only received a negative response from 10 dentists and five hygienist/EFDAs. Another item revealed that over half of the dentists and hygienist/EFDAs would volunteer to provide care for HIV-infected patients if the rest of their clinic staff refused. About half of the respondents did express concern that they would have many HIV patients assigned to them if they displayed a willingness to treat these patients. The vast majority indicated they would follow VA guidelines regarding the obligation to care for infectious patients. Furthermore, even if they could legitimately refer, the vast majority of respondents indicated that they would treat HIV-infected patients (Figure 3). About 89 percent of the dentists and 83 percent of the hygienist/EFDAs were in agreement with this statement.

\section{Discussion}

When examining the results of this survey, some differences between VA dental personnel and privatedental practitioners become apparent. Compared to private practitioners (5-9), a much larger proportion of VA dental personnel knowingly are involved in the treatment of HIV-infected patients. VA dental personnel also quite clearly express a much higher willingness to provide care to these patients. Studies of non-VA dental personnel show that the percent indicating a willingness to treat ranges from about 20 percent to 60 percent of respondents $(1,5,7,9-13)$. Willingness of up to 70 percent was seen in two of the non-VA surveys, which asked about the treatment of "suspected" asymptomatic patients (8) and of regular patients who became HIV-infected (14). In this VA survey, 98 percent of the dentists and 96 percent of the hygienist/EFDAs indicated they would treat HIVinfected patients. Even if the option for legitimate referral existed, 89 percent of the VA dentists and 83 percent of the hygienist/EFDAs still indicated they would treat these patients. Although anxiety, actual clinical exposures, and perceived risks of clinical exposures might be expected to impact negatively on willingness to treat HIV-infected individuals, the results of this survey do not support such expected relationships in this population of VA dental personnel.

Differences also are apparent when comparing surveys of private practice dental personnel to surveys of physicians and nurses, with 60 percent to 70 percent of nurses and 80 percent of physicians indicating a willingness to treat HIV-infected patients $(15,16)$. The high willingness of VA dentists and hygienist/EFDAs to treat infectious patients, like physicians and nurses, may be related to the fact that VA dental personnel are hospital based.VA dental personnel therefore may have different perceptions of their clinical practice and the types of patients they are likely to encounter than private practicing dental personnel.

With practically all VA dental personnel involved in the treatment of known HIV-infected patients, a relationship between experience in treating these patients and greater willingness to treat also is suggested. The fact that most VA dental personnel have treated HIV-infected patients obviously would indicate that some level of willingness was present at some point. A question remains, however, as to the exact relationship between willingness to treat and the actual treatment of HIV-infected patients. While a sufficient level of willingness would have to be present to treat the first HIV-infected patient, experience and increased confidence may feed back into an increased willingness to treat additional 
HIV-infected patients.

Comparisons among surveys of willingness to treat are somewhat complicated by how the HIV-infected patient is defined in the different surveys. In their 1990 survey, Sadowsky and Kunzel reported that 60 percent of dentists were willing to treat HIV-infected individuals (10). These investigators pointed out that although their results indicated that the proportion of dentists willing to treat HIV patients appeared to be rising dramatically from levels found in the earlier ADA surveys (1), some of this increase may have been due to ADA survey items inquiring about treating AIDS patients, while their survey only asked about the treatment of HIV-infected individuals. Dentists may be less willing to treat patients with symptoms of AIDS than to treat asymptomatic HIV-infected patients. Due to these differences in survey item wording and the different time frames, comparisons between the VA survey and the survey of Sadowsky and Kunzel (10) on willingness are probably more valid than comparisons to the ADA survey (1).

While willingness to treat HIV-infected patients was high, most respondents nevertheless indicated that incomplete access to the HIV status of patients decreased their confidence in treating patients. Over half of the respondents in this survey also indicated they should have the right to decide whether to treat HIV-infected patients and felt a professional rather than a legal obligation to treat. These results would seem concordant. The responses to items on willingness to treat cited earlier would still indicate, however, that although half of the respondents think they should have the right to decide whether to treat, the vast majority would still provide treatment to HIV-infected patients.

The increase in certain types of clinical injuries seen between the 1988 and 1991 VA surveys might indicate a more relaxed attitude toward avoiding such exposures, or may be a result of increased recall due to increased apprehension and awareness of such events as the number of infectious patients increases. This dependence on the recall of the respondents may make the latter explanation more plausible, given the level of doubt in the ability of presently recommended methods of infection control to protect dental personnel from infection, and the high level of perceived risk and apprehension relating to clinical exposures seen in the survey results.

The perceived risk of the respondents for hepatitis B infection and particularly for HIV infection generally was much higher than actual risks of infection associated with various occurrences or activities based on present knowledge. Actual risk of infection from an exposure during treatment of an HIV-infected patient generally has been estimated to be less than 1 percent (17-19). The high proportion of respondents who would choose a career not involving exposure to HIV if given another chance further indicates the high perceived risk and impact that the issue of treating HIV-infected patients has had on the attitudes of VA dental personnel about their profession.

A related area that generally has not been addressed in studies is how anxiety and fear cause changes in the way treatment decisions are made for HIV-infected patients. The extent to which changes in clinical behavior and decision making occur as a result of dentists' attitudes or concerns and any effect on the appropriateness of treatment is an area requiring further research.

Behaviors that reduce the potential for infection of dental personnel and other patients are considered of primary importance in the treatment of infectious patients. The hepatitis $B$ vaccination rates of 90 percent for VA dentists and 94 percent for VA hygienist/EFDAs compares favorably with the 60 percent rate found in the 1988 ADA national survey (1). Based on the VA survey responses, there also is evidence of a higher level of desired behavior related to infection control procedures in the VA than among private practitioners. The use of gloves, surgical masks, surgical gowns, and autoclavable handpieces was higher in the 1988 and 1991 VA surveys than in the 1986 and 1988 ADA surveys (1). The hospital setting in which most VA dental clinics are situated and control over clinic procedures by the VA may account for much of this difference.

Overall, VA dental personnel report a high level of positive behaviors relating to infection control and treatment, and a high willingness to treat HIV-infected patients. While these desirable important behaviors and attitudes seem to be present, there appears to be a need for efforts to decrease the anxiety level and perceived risk of VA dental personnel in treating infectious patients, while continuing efforts to further reduce actual exposure risk.

\section{Acknowledgments}

The authors would like to thank the Department of Veterans Affairs Office of Dentistry and all those who participated in thesurvey. Without their cooperation and support, this research would not have been possible.

\section{References}

1. Verrusio AC, Neidle EA, Nash KD, Silverman Jr. S, Horowitz AM, Wagner KS. The dentist and infectious diseases: a national survey of attitudes and behavior. J Am Dent Assoc 1989;118:553-62.

2. Centers for Disease Control. Recommended infection-control practices for dentistry. MMWR Morb Mortal Wkly Rep 1986;35:237-42.

3. Centers for Disease Control. Recommendations for prevention of HIV transmission in health care settings. MMWR Morb Mortal Wkly Rep 1987;36(Suppl 2S):1-18S.

4. ADA Council on Dental Materials, Instruments, and Equipment, Council on Dental Education, and Council on Dental Therapeutics. Infection control recommendations for the dental office and the dental laboratory. J Am Dent Assoc 1988;116:241-8.

5. Kunzel C, Sadowsky D. Comparing dentists' attitudes and knowledge concerning AIDS: differences and similarities by locale. J Am Dent Assoc 1991;122:55-61.

6. Dove SB, Cottone JA. Knowledge and attitudes of Texas dentists concerning AIDS. Am J Dent 1990;3:5-8.

7. Hastreiter RJ, Roesch MH, Heckert KA, Danila RN. Infection control practices and beliefs of Minnesota dental hygienists and dental assistants. J Dent Hyg 1990;64:376-81.

8. Moretti RJ, Ayer WA, Derefinko A. Attitudes and practices of dentists regarding HIV patients and infection control. Gen Dent 
1989:37:144-7.

9. Hardie J. Dentists' attitudes towards AIDS. A survey. J Can Dent Assoc 1987;11:823-5.

10. Sadowsky D, Kunzel C. Are you willing to treat AIDS patients? J Am Dent Assoc 1991;122:28-32.

11. DiAngelis AJ, Martens LV, Little JW, Hastreiter RJ. Infection control practices of Minnesota dentists: changes during 1 year. J Am Dent Assoc 1989;118:299-303.

12. Rydman RJ, Yale SH, Mullner RM, Whitels D, Vaux K. Preventive control of AIDS by the dental profession: a survey of practices in a large urban area. J Public Health Dent 1990;50:7-12.

13. Cade IE, Lancaster DM. Protective measures in dental treatment. J Am Coll Dent 1990;57:7-11.

14. Pitts NB, Nuttall NM. Precautions reported to be used against cross-infection and attitudes to the dental treatment of HIV-positive patients in routine clinical dental practice in Scotland. J Dent 1988;16:258-63.
15. Colombotos J, Messeri P, Burgunder M, Elinson J, Gemson D, Hynes M. Physicians, nurses, and AIDS: preliminary findings from a national study. Agency for Health Care Policy and Research, US Department of Health and Human Services, 1991; AHCPR pub no 91-0024.

16. Wiley K, Health L, Acklin M. Care of AIDS patients: student attitudes. Nurs Outlook 1988;9:244-5.

17. Centers for Disease Control. Update: acquired immunodeficiency syndrome and human immunodeficiency virus infection among health-care workers. MMWR Morb Mortal Wkdy Rep 1988;37:22934,239 .

18. Centers for Disease Control. Recommendations for preventing transmission of infection with HTLV-III/LAV in the workplace. MMWR Morb Mortal Wkly Rep 1985;34:682-6,691-5.

19. Henderson DK, Fahey BJ, Willy M, et al. Risk for occupational transmission of human immunodeficiency virus type 1 (HIV-1) associated with clinical exposures. Ann Intern Med 1990;113:740-6. 